\title{
Chlamydia psittaci Triggers the Invasion of H9N2 Avian Influenza Virus by Impairing the Functions of Chicken Macrophages
}

\author{
Jun Chu ${ }^{1,2}$, Yongxia Guo ${ }^{3}$, Guanlong Xu ${ }^{4}$, Qiang Zhang ${ }^{3}$, Zonghui Zuo ${ }^{3}$, Qiang $\mathrm{Li}^{3}$, \\ Yihui Wang ${ }^{3}$ and Cheng $\mathrm{He}^{1,3, * \mathbb{D}}$ \\ 1 College of Life Science and Engineering, Foshan University, Foshan 528000, Guangdong, China; \\ chujcau2016@tom.com \\ 2 Institute of Animal Husbandry and Veterinary Medicine, Beijing Academy of Agriculture and Forestry \\ Services, Beijing 100097, China \\ 3 Key Lab of Animal Epidemiology and Zoonosis of the Ministry of Agriculture, College of Veterinary \\ Medicine, China Agricultural University, Beijing 100193, China; gaoyxcau732@sohu.com (Y.G.); \\ zhangqcauhp@sohu.com (Q.Z.); zuozgcau@2980.com (Z.Z.); liqiang5973@163.com (Q.L.); \\ wyhairforce@126.com (Y.W.) \\ 4 National Reference Lab for Animal Brucellosis, China Institute of Veterinary Drug Control, \\ Beijing 100082, China; xuguanlongw@163.com \\ * Correspondence: hecheng@cau.edu.cn; Tel.: +86-010-62733613
}

Received: 3 February 2020; Accepted: 17 April 2020; Published: 21 April 2020

Simple Summary: Chlamydia psittaci, an obligate, intracellular, Gram-negative bacterium and economically relevant pathogen in poultry and pet bird, could cause psittacosis/ornithosis, and is also a human pathogen causing atypical pneumonia after zoonotic transmission. H9N2 influenza virus, a low pathogenic avian influenza viruses' subtype, has become endemic in different types of domestic poultry in lots of countries, resulting in great economic loss due to reduced egg production or high mortality associated with coinfection with other pathogens. These two pathogens are easily mixed with other pathogens to aggravate the disease, and often cause mixed infection in clinics. Co-infection of $C$. psittaci with H9N2 commonly induces severe pneumonia and high mortality in specific pathogen-free (SPF) chickens. According to previous studies, we postulated that $C$. psittaci infection may beneficial for the replication of H9N2 in HD11. Consequently, in this study, we clarify the pathogenic mechanism of coinfection with C. psittaci and H9N2 in the chicken macrophage cell line HD11, which is the first study of the coinfection of $C$. psittaci and H9N2 in vitro.

\begin{abstract}
In a pilot study, simultaneous infection with Chlamydia psittaci (C. psittaci) and H9N2 virus induced $20 \%$ mortality and severe avian airsacculitis, shedding light on animal models of poultry respiratory diseases. However, the pathogenesis is still unclear. In the current study, we hypothesized that $C$. psittaci infection execrates macrophage function and facilitates H9N2 infection. To explore the potential mechanism, we studied the effect of $C$. psittaci and H9N2 on the functions of HD11 cells in vitro by simultaneous infection of $C$. psittaci and H9N2. At the same time, we used infection with C. psittaci or $\mathrm{H} 9 \mathrm{~N} 2$ alone as the control groups. The results showed that coinfection with C. psittaci and H9N2 could significantly aggravate the mortality of HD11 cells compared to C. psittaci or H9N2 infection alone. In addition, coinfection with C. psittaci and H9N2 did not induce high C. psittaci loads compared to C. psittaci infection alone at 12- and 24-hours post-inoculation (hpi), but coinfection with C. psittaci and H9N2 could increase the loads of H9N2 compared to H9N2 alone in HD11 cells at 12 hpi. More importantly, inducible nitric oxide synthase (iNOS) expression levels, enzyme activity, nitric oxide (NO) production, and phagocytosis were reduced significantly in the group with C. psittaci and H9N2 coinfection compared to those of H9N2 or C. psittaci alone at 24 hpi. Finally, C. psittaci infection induced robust expressions of type Th2 cytokines interleukin (IL)-4 and IL-10, while interferon gamma
\end{abstract}


(IFN- $\gamma$ ) and tumor necrosis factor- $\alpha$ (TNF- $\alpha$ ) displayed a significant decrease compared to H9N2 infection alone at $24 \mathrm{hpi}$. All the above data indicate that C. psittaci infection can facilitate H9N2 invasion and to aggravate severe avian airsacculitis by impairing macrophage functions.

Keywords: Chlamydia psittaci; avian influenza virus H9N2; coinfection; macrophage functions; avian airsacculitis

\section{Introduction}

Chlamydia psittaci (C. psittaci) is an obligate, intracellular, Gram-negative bacterium and an economically relevant pathogen in poultry and pet birds, where it causes psittacosis/ornithosis, as well as being a human pathogen that causes atypical pneumonia after zoonotic transmission [1]. In the period from 1890 to 1930, human psittacosis outbreaks in Europe and America can all be attributed to contact with sick birds [2]. Later, due to improved knowledge on etiology and epidemiology, as well as the use of antimicrobials in therapy, large outbreaks became rare exceptions. However, what should still not be ignored is that chlamydiosis is still widespread and represents a major factor of economic loss to the poultry industry, as well as a permanent risk for zoonotic transmission to human [3]. Apart from overt clinical manifestations, latent C. psittaci infection can cause recurrent and chronic diseases that have an adverse effect on the production performance of animals. Recently, C. psittaci prevalence in birds has been reported around the world. For example, Dickx found $58.0 \%$ prevalence in feral Canada geese (Branta canadensis) in Belgium [4]; meanwhile, Cong's study revealed a high C. psittaci seroprevalence in pet birds, market-sold adult chickens, ducks, and pigeons in north-western China $[5,6]$. In our previous survey, C. psittaci-specific serum antibodies and antigen were detected in $10.0 \%$ and $26.7 \%$ of the studied birds, respectively, suggesting that C. psittaci prevalence in Beijing is like that reported in European cities. Moreover, the highly positive antigens in pigeon fanciers suggest that exposure and possible zoonotic transmission of $C$. psittaci from racing pigeons to humans highlights an ongoing form of transmission [7]. The study of Wang et al. demonstrated the existence $(22.22 \%)$ of $C$. psittaci infection in pigeons in northern China [8].

C. psittaci causes respiratory and systemic infection in birds, and continues for a long time under unfavorable conditions. C. psittaci and other pathogens can cause mixed infection in birds and poultry [9]. There are numerous reports that viruses and bacteria often act synergistically in causing diseases in humans or animals. In recent years, with the continuous expansion of the poultry industry, the incidence of various diseases has increased year by year, and the mixed infection of Chlamydia and other pathogens seriously affects the diagnosis and prevention of poultry disease and causes great economic loss to the poultry industry.

The H9 subtype of avian influenza virus (AIV) is one of the subtypes most frequently found in circulation in domestic chickens [10]. H9N2 influenza virus, a low pathogenic avian influenza virus subtype, has become endemic in different types of domestic poultry in multiple countries due to the occurrence of virulent strains, resulting in great economic losses, such as reduced egg production and high mortality associated with coinfection with other pathogens [11]. What is worse is that more human infections with H9N2 have been reported since 2014. In a previous study, the results showed that poultry workers had an overall H9N2 seroprevalence of $1.87 \%$ and a seroprevalence of $8.78 / 1000$ person-years, which is significantly higher than those of H7N9 and H5N1 [12]. More importantly, H9N2 has particularly significant implications due to its widespread circulation in domestic poultry, especially in the presence of other coinfecting pathogens. For example, coinfection with Escherichia coli (E. coli) and H9N2 caused more serious synergistic pathogenic effects, and indicates the role of both pathogens as complicating factors in poultry infections [13]. Some researchers have also studied the effect of two major pathogens—namely, H9N2 and avian infectious bronchitis (IBV)—in multiple infections [14]. 
Because C. psittaci and H9N2 are not highly pathogenic, the extent of infection in poultry and humans is likely to remain underestimated. However, these two pathogens are easily mixed with other pathogens, and thus can aggravate diseases. More recently, it was reported that C. psittaci and H9N2 often cause mixed infections in clinic. Our previous study found that C. psittaci infection increases the mortality of avian influenza virus H9N2 by suppressing the host immune response [15]. In addition, coinfection of C. psittaci with H9N2, Ornithobacterium rhinotracheale (ORT), and Aspergillus fumigatus (A. fumigatus) contributes to severe pneumonia and a high mortality in specific pathogen-free (SPF) chickens, explaining why severe avian airsacculitis is prevalent in the winter season in northern China [16].

Macrophages play critical roles in innate and adaptive immunity against chlamydial infections. The depletion of macrophages from mice prior to infection with Chlamydia muridarum (C. muridarum) and C. psittaci results in increased morbidity and pathogen burdens [17,18]. Macrophage activities may not contribute to pathogen clearance, because C. psittaci is able to survive and deliver to other tissues by using the macrophage as a "vehicle" [19]. Macrophages activated by interferon gamma (IFN- $\gamma$ ) and lipopolysaccharide (LPS) or other microbial pathogen-associated molecular patterns (PAMPs) are associated with increased mortality of macrophages, nitric oxide (NO) production, secretions of inducible nitric oxide synthase (iNOS), and pro-inflammatory cytokines [20]. In this study, we illustrate the pathogenic mechanism of coinfection with C. psittaci and H9N2 in the chicken macrophage cell line HD11. Based on previous animal studies, we postulate that C. psittaci infection might be beneficial for the replication of H9N2 in HD11 macrophages by impairing the macrophage functions.

\section{Materials and Methods}

\subsection{Cells and Virus}

The chicken macrophage HD11 cells were kindly provided by Prof. Jian Qiao (College of Veterinary Medicine, China Agricultural University, Beijing, China). HD11 cells were cultured in Dulbecco's modified Eagle's medium (DMEM) (Gibco, United States) supplemented with 10\% fetal bovine serum (FBS) (Gibco, United States), $100 \mathrm{U} / \mathrm{mL}$ penicillin, and $100 \mu \mathrm{g} / \mathrm{mL}$ streptomycin (Gibco, United States) at $\mathrm{pH} 7.2$, and were kept at $37^{\circ} \mathrm{C}$ with $5 \%$ carbon oxide $\left(\mathrm{CO}_{2}\right)$. The Buffalo Green Monkey (BGM) cell-adapted C. psittaci 6BC strain used in the current study was housed in our laboratory. The C. psittaci 6BC standard strain was kindly provided by Prof. Yimou Wu (Institute of Pathogenic Biology, University of South China, Hengyang, Hunan Province, China) and the AIV H9N2/chicken/Shandong/2011 was isolated from broilers as described previously [21]. The susceptibility of HD11 cells to C. psittaci and H9N2 was measured by morphological changes, growth curves using 50\% tissue culture infective doses $\left(\mathrm{TCID}_{50}\right)$, and indirect immunofluorescence assay (IFA).

\subsection{Virus and Bacteria Titration}

The H9N2 AIV (H9N2/chicken/Shandong/2011) chicken embryo allantoic fluid was diluted 1000 times; then, 9 11-day-old SPF chicken embryos were inoculated with $0.2 \mathrm{~mL}$ and incubated in $37^{\circ} \mathrm{C}$ incubators. After $24 \mathrm{~h}$, the dead chicken embryos were abandoned and the rest were incubated for $48 \mathrm{~h}$ in the thermostat. After being at $4{ }^{\circ} \mathrm{C}$ refrigerators overnight, the chicken embryo uranic fluid was tested under aseptic conditions, and the hemagglutination-inhibition (HI) titers was measured-it was $\geq 7.0\left(\log _{2}\right)$ in the uranic solution and saved at $-80{ }^{\circ} \mathrm{C}$. Here, TCID 50 was applied to the HD11 cells to quantitate the virus titers, as described previously [22]. The HD11 cells were cultured in 96-well plates, and 10-fold dilutions of the virus were prepared in DMEM supplemented with 2\% FBS. The cultured cells were infected with the virus and then observed daily for cytopathic effects (CPE). The final virus titers were calculated by the Reed-Muench method to be $10^{3.86} \mathrm{TCID}_{50} / \mathrm{mL}$.

As for C. psittaci, the BGM cells were seeded on round coverslips and cultured in growth medium consisting of minimal essential medium (MEM) supplemented with 5\% fetal calf serum (FCS). Ten-fold dilutions of the inoculum were centrifuged at $3400 \times g$ for $1 \mathrm{~h}$ at $37^{\circ} \mathrm{C}$, and then incubated for $2 \mathrm{~h}$ 
at $37^{\circ} \mathrm{C}$. The growth medium was subsequently replaced by serum-free medium. After $48 \mathrm{~h}$ of incubation, the cells were fixed in absolute methanol for $10 \mathrm{~min}$. Chlamydial inclusions were detected by direct immunofluorescence using a monoclonal antibody conjugated to fluorescein isothiocyanate (FITC), diluted 1:5 in phosphate-buffered saline (PBS), at pH 7.4 (Imagen Chlamydia, Oxoid, France). The number of inclusion-forming units (IFU) per $\mathrm{mL}$ was assessed by counting the total number of inclusions on the whole coverslip of a countable inoculum dilution. A final titer of $4.05 \times 10^{8} \mathrm{IFU} / \mathrm{mL}$ was determined for the inoculum.

\subsection{Experimental Design}

The HD11 cells were cultured in DMEM with $10 \%$ FBS, seeded in a six-well cell culture plate at a concentration of $1 \times 10^{6}$ per well, and then kept at $37^{\circ} \mathrm{C}$ with $5 \% \mathrm{CO}_{2}$ for $24 \mathrm{~h}$. The coinfection group cells were infected with C. psittaci and H9N2 simultaneously. The C. psittaci- and H9N2-only infection groups were only infected with C. psittaci or H9N2, respectively. The infection doses of the two pathogens were both at a multiplicity of infection (MOI).

\subsection{Quantitative Real-Time Reverse Transcription PCR}

The total RNA was isolated using TRIzol agent (TransGen Biotech, Beijing, China), and each RNA sample was reverse-transcribed to complementary DNA (cDNA) by the PrimeScript RT Reagent Kit (Takara, Dalian, Liaoning Province, China). cDNA was used for quantitative real-time polymerase chain reaction (qRT-PCR) analysis. The sets of primer pairs of the two pathogens and of the nitric oxide synthase genes are listed in Table 1, and the primer pairs of cytokines can be found in Nang et al.'s paper [23]. For qRT-PCR reactions, the $25 \mu \mathrm{L}$ reaction mixture included $2 \mu \mathrm{L}$ cDNA, $12.5 \mu \mathrm{L}$ SYBR Premix Ex TaqTM II (Takara, Beijing, China), $1.0 \mu \mathrm{L}$ of forward primer and $1.0 \mu \mathrm{L}$ of reverse primer, and $8.5 \mu \mathrm{L}$ RNAase-free water (Takara, Beijing, China). The reaction conditions were $95^{\circ} \mathrm{C}$ for $3 \mathrm{~min}$, followed by 44 cycles of $95^{\circ} \mathrm{C}$ for $10 \mathrm{~s}$, then the specific melting temperature $(\mathrm{Tm})$ of a primer pair for $30 \mathrm{~s}$, and then $95^{\circ} \mathrm{C}$ for $10 \mathrm{~s}$ and $72{ }^{\circ} \mathrm{C}$ for $10 \mathrm{~s}$, using a Bio-Rad IQ5 Thermal Cycler (Bio-Rad). Glyceraldehyde-3-phosphate dehydrogenase (GAPDH) was selected as a reference gene. The expression fold changes were calculated using the $2^{-\Delta \Delta \mathrm{Ct}}$ method [24].

Table 1. The sequences of the chicken primer pairs used for quantitative real-time polymerase chain reaction (qRT-PCR).

\begin{tabular}{ccc}
\hline Gene & Forward Primer $\left(\mathbf{5}^{\prime} \mathbf{-} \mathbf{3}^{\prime} \mathbf{)}\right.$ & Reverse Primer $\left(\mathbf{5}^{\prime} \mathbf{- 3}^{\prime} \mathbf{)}\right.$ \\
\hline C. psittaci & GTCAGCTATAACGCCGTG & CCAACTCCCATGATGTGACG \\
H9N2 AIV & CTGGAATCTGAGGGAACTTACAAA & GAAGGCAGCAAACCCCATT \\
iNOS & AGGCCAAACATCCTGGAGGTC & TCATAGAGACGCTGCTGCCAG \\
GAPDH & CAACACAGTGCTGTCTGGTGGTA & ATCGTACTCCTGCTTGCTGATCC \\
\hline
\end{tabular}

\subsection{Determination of Cell Mortality}

Cell mortality was detected by a CellTox Green Cytotoxicity Assay Kit (Promega, Wisconsin, United States). The detection system uses a proprietary asymmetric cyanine dye, which is blocked by living cells but can stain the DNA of dead cells. When the dye binds with DNA, it emits fluorescence. Therefore, the fluorescence signal produced by the dye bound to the dead cell DNA is directly proportional to the cytotoxicity. We operated strictly according to the protocol, adding $50 \mu \mathrm{L}$ cells with a concentration of $1 \times 10^{5} / \mathrm{mL}$ to the 96 -well cell culture plate. Then, we added $100 \mu \mathrm{L}$ CellTox ${ }^{\mathrm{TM}}$ Green reagent (Madison, WI, USA), and after incubation for $15 \mathrm{~min}$, it was put into a fluorescence enzyme labeling instrument. After $1 \mathrm{~min}$ of simple oscillation, the fluorescence signal value was detected at 485-500 nm Ex/520 530 nm Em wavelength. 


\subsection{Determination of $i N O S$ Activity}

The inducible nitric oxide synthase (iNOS) activity was detected by a Nitric Oxide Synthase (NOS) Activity Assay Kit (BioVision, SMB, Milpitas, CA, United States). Briefly, we added 100-200 $\mu$ L cold NOS Assay Buffer containing protease inhibitor cocktail to fresh cells $\left(2-5 \times 10^{6}\right)$, which was then homogenized to disrupt the cells. The tissue or cell homogenate was centrifuged at $10,000 \times g$ and $4{ }^{\circ} \mathrm{C}$ for $10 \mathrm{~min}$. The clarified supernatant was transferred to a fresh pre-chilled tube and kept on ice. The protein concentration was measured, and the lysates were used immediately to assay NOS activity. Then, 30-60 $\mu \mathrm{L}$ (200-400 $\mu \mathrm{g}$ protein) of cell/tissue homogenate or purified protein was measured into the desired wells in a 96-well plate. For the positive control, NOS enzyme was diluted 1:20 in NOS Dilution Buffer just before use. Next, $5-10 \mu \mathrm{L}$ of the diluted NOS enzyme was added into the desired well(s), and the volume of the sample and the positive control wells were made up to $60 \mu \mathrm{L} /$ well with the NOS Assay Buffer. Enough reaction mixes for the number of wells (standards, positive control, and sample) were prepared to be analyzed, which were then mixed well and incubated at $37^{\circ} \mathrm{C}$ for $1 \mathrm{~h}$. After incubation, $90 \mu \mathrm{L}$ of NOS Assay Buffer was added to the standard, positive control, and sample wells, and subsequently $5 \mu \mathrm{L}$ of the enhancer was added into each well, which were then mixed and incubated at room temperature for $10 \mathrm{~min}$. After this, $50 \mu \mathrm{L}$ of Griess Reagent 1 and $50 \mu \mathrm{L}$ of Griess Reagent 2 were added to the standard, positive control, and sample wells, which were then mixed and incubated for $10 \mathrm{~min}$, before the absorbance $(540 \mathrm{~nm})$ was read using a microplate reader. The nitrite standard curve was plotted and the iNOS activity calculated according to the formula: sample iNOS activity $=$ nitrite amount in sample well from standard curve/(reaction time $\times$ amount of protein $)=$ $\mathrm{pmol} / \mathrm{min} / \mu \mathrm{g}=\mathrm{mU} / \mathrm{mg}$.

\subsection{Nitrite Quantification}

Nitrite levels were determined by colorimetric assay based on the Griess reaction (Beyotime, Haimen, Jiangsu Province, China), using sodium nitrite standards. Briefly, $100 \mu \mathrm{L}$ of cell-free pretreated supernatant was mixed with $100 \mu \mathrm{L}$ of Griess reagent, and after $10 \mathrm{~min}$, the absorbance was measured at $540 \mathrm{~nm}$ wavelength. Using a standard curve, the absorbance of the samples was converted to micromolar nitric oxide (NO).

\subsection{Detection of Cell Phagocytosis}

The phagocytosis of macrophages was detected by a fluorescein-labeled Escherichia coli $\mathrm{K}-12$ BioParticles of Vybrant Phagocytosis Assay Kit (ThermoFisher, MA, United States). Briefly, $100 \mu \mathrm{L}$ of the prepared fluorescent BioParticle suspension was added to all the negative control, positive control, and experimental wells, and incubated for $2 \mathrm{~h}$. The BioParticle was removed and $100 \mu \mathrm{L}$ of the prepared trypan blue suspension was immediately added to all wells, before incubating for $1 \mathrm{~min}$ at room temperature. The experimental and control wells of the microplate were read in the fluorescence plate reader using $\sim 480 \mathrm{~nm}$ excitation, $\sim 520 \mathrm{~nm}$ emission, and the appropriate sensitivity settings. The net phagocytosis and the response to the phagocytosis effector agent were then calculated. First, the average fluorescence intensity of a group of negative control wells was subtracted from that of a group of positive control wells to yield the net positive reading. Second, the average fluorescence intensity of a group of negative-control wells was subtracted from that of a group of identical experimental wells to obtain the net experimental reading. The phagocytosis response to the effector could then be expressed as follows: $\%$ effect $=$ net experimental reading/net positive reading $\times 100 \%$.

\section{9. mRNA Expression of Cytokines by RT-PCR and Quantitative Secretions by ELISA Kits}

The total RNA was extracted from HD11 cells by applying Trizol (TransGen Biotech, Beijing, China), and was subsequently treated with a DNA-free kit to filter DNA contamination. Relative quantification of interleukin (IL)-1 $\beta$, IL-2, IL-6, IL-10, Interferon gamma (IFN- $\gamma$ ) and tumor necrosis factor- $\alpha$ (TNF- $\alpha)$ was performed using an SYBR Green PCR Master Mix kit (Takara, Dalian, China), 
as previously described [15]. As for cytokine determination, roughly $200 \mu \mathrm{L}$ aliquots of each sample were used to measure the cytokines IL-1 $\beta$, IL-2, IL-6, IL-10, IFN- $\gamma$, and TNF- $\alpha$ with commercial ELISA kits (Kingfisher Biotech Inc., Saint Paul, MN, United States).

\subsection{Statistical Analysis}

The data are presented as averages \pm standard deviations (SDs), as indicated. Statistical comparisons were analyzed with one-way ANOVA with the Least-Significant Difference (LSD) post hoc test. All of the statistical analyses were performed with SPSS version 25.0. When $p>0.05$, the results were not significant; when $p<0.05$, the results were significantly different; when $p<0.01$, the results were extremely significantly different.

\section{Results}

\subsection{Coinfection with C. psittaci and H9N2 Aggravated the Mortality of Macrophages}

To study the effect of coinfection with C. psittaci and H9N2 on the mortality of HD11 cells, we used fluorescent dye to detect cell membrane integrity in order to determine cell death rate. A significant increase in the mortality of HD11 cells was determined in the C. psittaci + H9N2 group, as compared to the groups of $\mathrm{H} 9 \mathrm{~N} 2$ or $C$. psittaci alone at 12 and $24 \mathrm{hpi}(p<0.05)$. In addition, no statistical difference of HD11 mortality was found between the groups of $C$. psittaci and H9N2 infection alone at 12 and 24 hpi (Figure 1a,b).
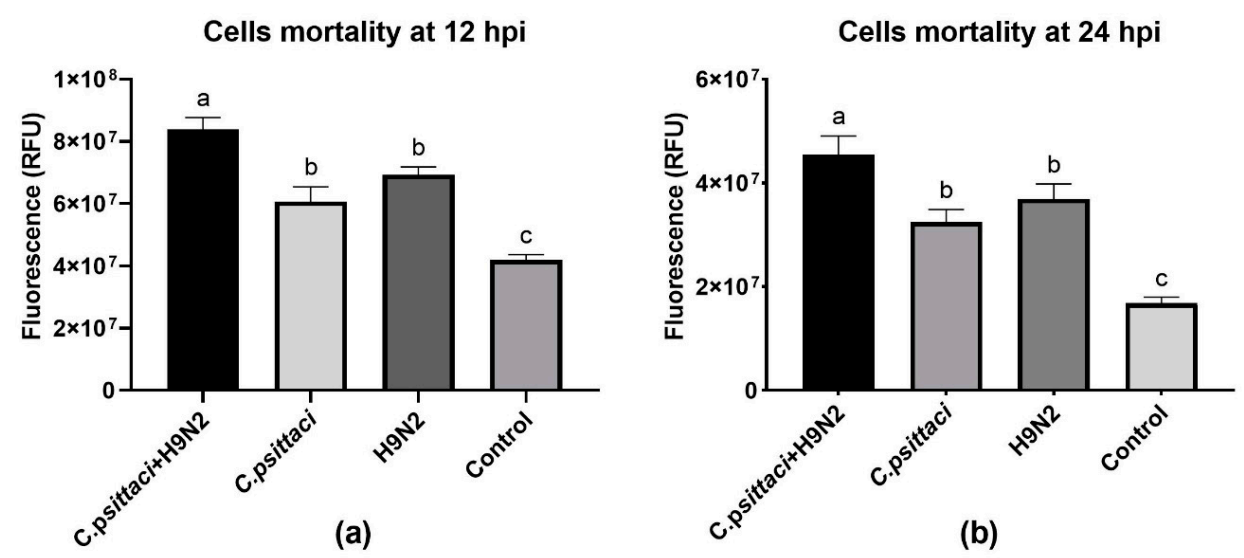

Figure 1. The cell mortality of HD11 cells was tested post-infection with C. psittaci or H9N2 alone, or via coinfection. The cell mortality of HD11 cells was tested at 12 hours post-inoculation (hpi) (a), or at 24 hpi (b). Data shown represent the mean \pm standard deviation (SD), and the error bars represent the standard deviations from four independent experiments. One-way ANOVA with the Least-Significant Difference (LSD) post-hoc test was used for statistical analysis of the two different groups. Bars with the same lower-case letters in two different columns show no significant difference $(p>0.05)$, and bars with different lower-case letters in two different columns show a significant difference $(p<0.05$ or $p<0.01$ ). A significant increase in the mortality of HD11 cells was detected in the C. psittaci + H9N2 group, as compared to H9N2 or C. psittaci alone group at 12 and 24 hpi $(p<0.05)$.

\subsection{Coinfection with C. psittaci and H9N2 Reduced Chlamydial Loads and H9N2 Virus Loads}

To study the effect of coinfection with C. psittaci and H9N2 on the pathogen loads of HD11 cells, we detected the replication levels of C. psittaci and H9N2 by RT-PCR in HD11 cells at 12 and 24 hpi. As for the replication levels of C. psittaci, a significant reduction was found in the C. psittaci + H9N2 group, as compared to that of the C. psittaci group at 24 hpi $(p<0.01)$ (Figure 2b). Regarding H9N2 loads, higher virus loads were found in the C. psittaci + H9N2 group than in the H9N2 group at 12 hpi $(p<0.01)$ (Figure 2c), but were significantly lower in the C. psittaci + H9N2 group than those in the H9N2 group at 24 hpi $(p<0.01)$ (Figure $2 \mathrm{~d})$. 
C. psittaci loads at $12 \mathrm{hpi}$

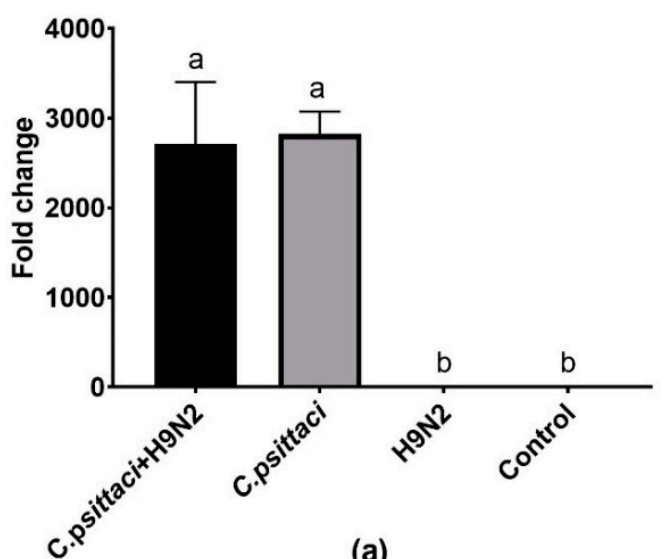

(a)

H9N2 loads at $12 \mathrm{hpi}$

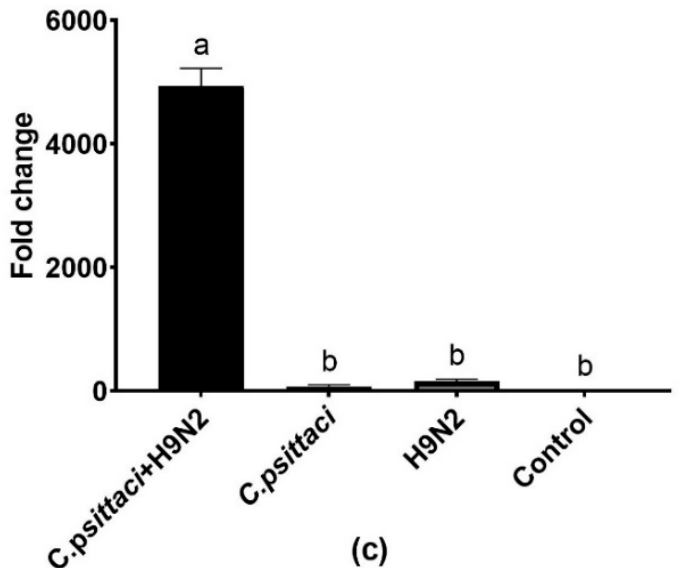

C. psittaci loads at $24 \mathrm{hpi}$

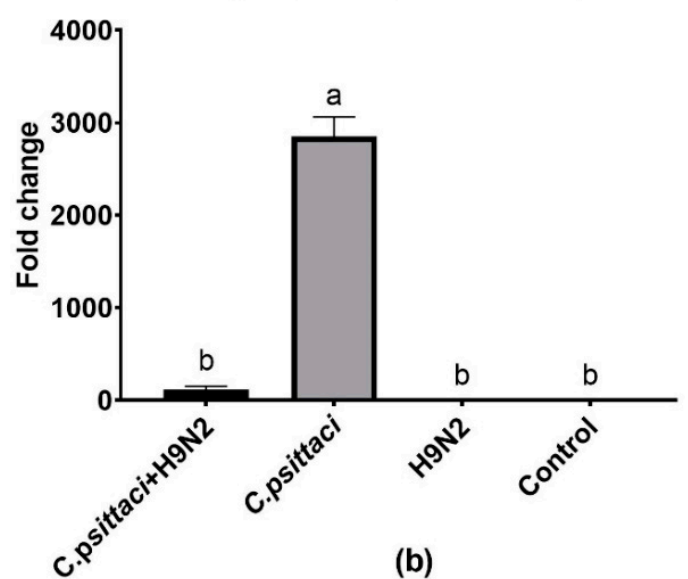

H9N2 loads at $24 \mathrm{hpi}$

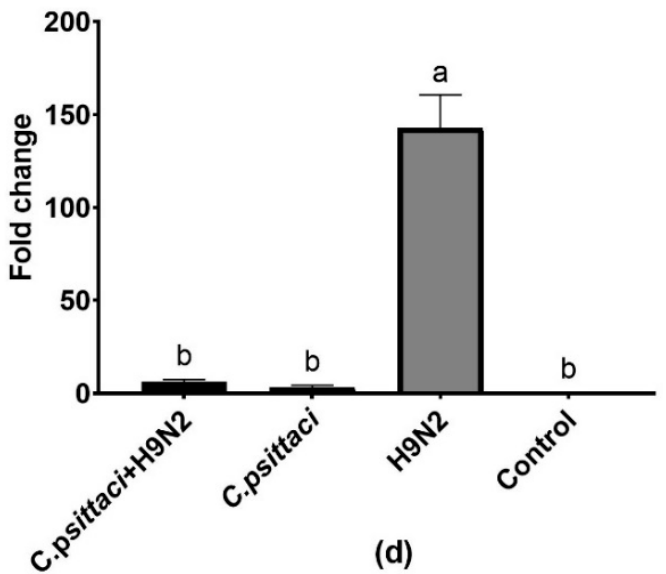

Figure 2. The effect of coinfection on pathogen loads. The pathogen loads of HD11 cells were tested at 12 and 24 hpi with C. psittaci or H9N2 alone, or via coinfection. The C. psittaci loads of HD11 cells were tested at 12 (a) and 24 (b) hpi, and the H9N2 loads of HD11 cells were tested at 12 (c) and 24 (d) hpi. A significant reduction of $C$. psittaci loads was found in the C. psittaci + H9N2 group, as compared to that of the C. psittaci group at $24 \mathrm{hpi}(p<0.01)$. Moreover, lower H9N2 loads were found in the C. psittaci $+\mathrm{H} 9 \mathrm{~N} 2$ group compared to those of the H9N2 group at $24 \mathrm{hpi}(p<0.01)$.

\subsection{Coinfection with C. psittaci and H9N2 Downregulated iNOS Activity of HD11 Cells}

To study the effect of coinfection with C. psittaci and H9N2 on the iNOS activity of HD11 cells, we detected the relative expression level of iNOS mRNA by RT-PCR and the enzyme activity by test kits. Lower iNOS expression levels were induced in the C. psittaci + H9N2 group than in the C. psittaci group $(p<0.05)$ or the H9N2 group $(p<0.01)$ at 24 hpi (Figure 3b). As for the determination of iNOS activity, a similar reduction was observed in the C. psittaci + H9N2 group, as compared to the C. psittaci group ( $p<0.05$ ) or the H9N2 group $(p<0.01)$ at 24 hpi (Figure 3d). Moreover, both iNOS and its activity were significantly different between the H9N2 group and the $C$. psittaci group at the two time points $(p<0.05)$. 
iNOS relative expression at $12 \mathrm{hpi}$

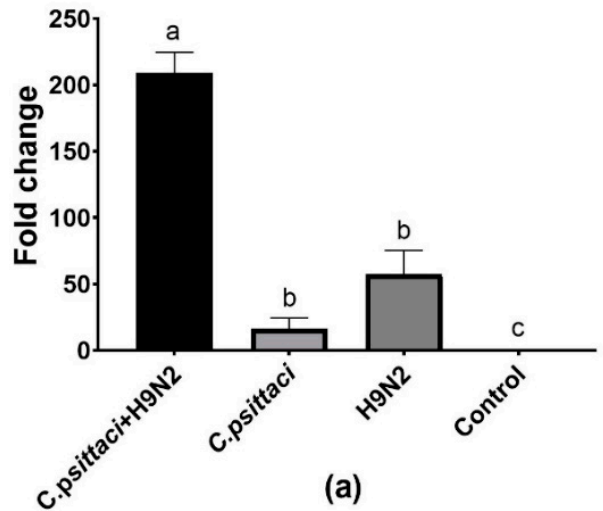

iNOS activity at $12 \mathrm{hpi}$

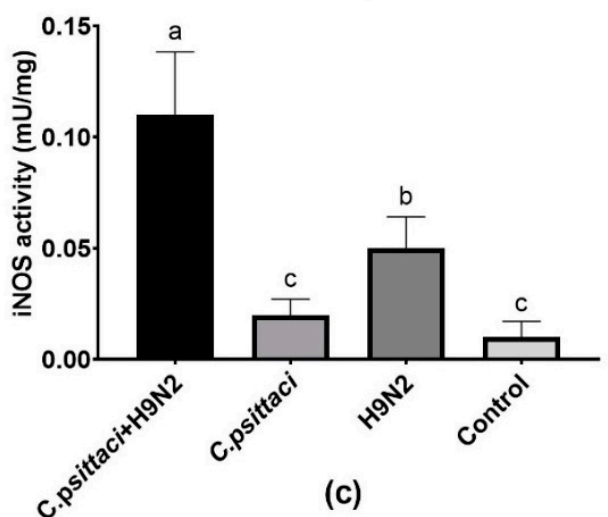

iNOS relative expression at $24 \mathrm{hpi}$

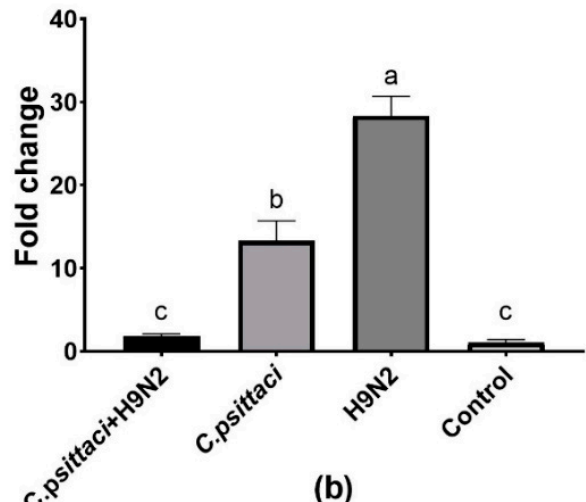

iNOS activity at $24 \mathrm{hpi}$

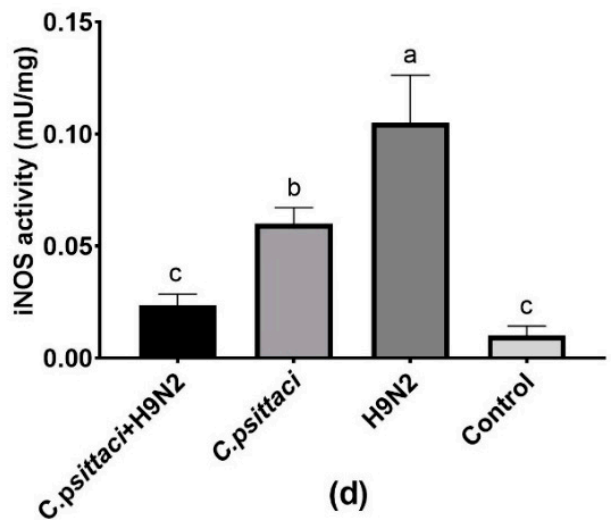

Figure 3. The effect of coinfection on inducible nitric oxide synthase (iNOS) expression and activity. The iNOS expression and activity of HD11 cells were tested post-infection with C. psittaci or H9N2 alone, or via coinfection. The iNOS expression of HD11 cells was tested at 12 (a) and 24 (b) hpi, and the iNOS activity of HD11 cells was tested at 12 (c) and 24 (d) hpi. Lower iNOS expressions were induced in the $C$. psittaci $+\mathrm{H} 9 \mathrm{~N} 2$ group, as compared to those of $C$. psittaci alone $(p<0.05)$ or H9N2 alone $(p<0.01)$ at $24 \mathrm{hpi}$. As for iNOS activity, a significant reduction was observed in the C. $p$ sittaci $+\mathrm{H} 9 \mathrm{~N} 2$ group, as compared to the C. psittaci group $(p<0.05)$ or the H9N2 group $(p<0.01)$ at 24 hpi.

\subsection{Coinfection with C. psittaci and H9N2 Reduced the NO Production of HD11 Cells}

The synthesized and released NO levels of HD11 cells were determined by a total nitric oxide test kit. Obviously, a significant increase in NO production was detected in the C. psittaci + H9N2 group, as compared to other groups at $12 \mathrm{hpi}$ (Figure 4a). However, lower NO production was induced in the C. psittaci + H9N2 group and the C. psittaci group than in the H9N2 group at 24 hpi $(p<0.05)$. No significant difference was found between the C. psittaci $+\mathrm{H} 9 \mathrm{~N} 2$ group and the C. psittaci group at 24 hpi (Figure 4b).

\subsection{Coinfection with C. psittaci and H9N2 Downregulated the Phagocytosis of HD11 Cells}

The phagocytosis of HD11 cells was determined by a fluorescent microspheres kit. Lower phagocytosis was found in the $C$. psittaci group $(p<0.05)$ than in the $C$. psittaci + H9N2 group or the H9N2 group $(p<0.05)$ at 12 hpi (Figure 5a). Later, the C. psittaci + H9N2 group reduced phagocytosis significantly, as compared to the $C$. psittaci group $(p<0.05)$ or the H9N2 group $(p<0.01)$ at 24 hpi. No significant difference in phagocytic activity was found between the H9N2 group and the control group $(p>0.05)$ (Figure 5b). 
NO synthesized at $12 \mathrm{hpi}$

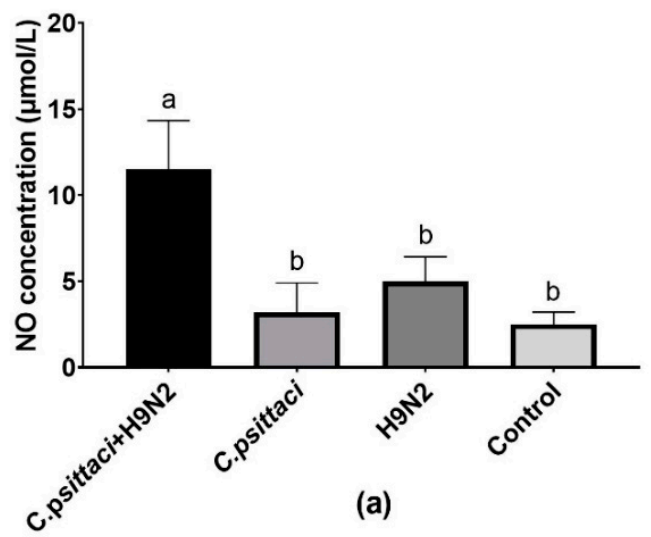

NO synthesized at $24 \mathrm{hpi}$

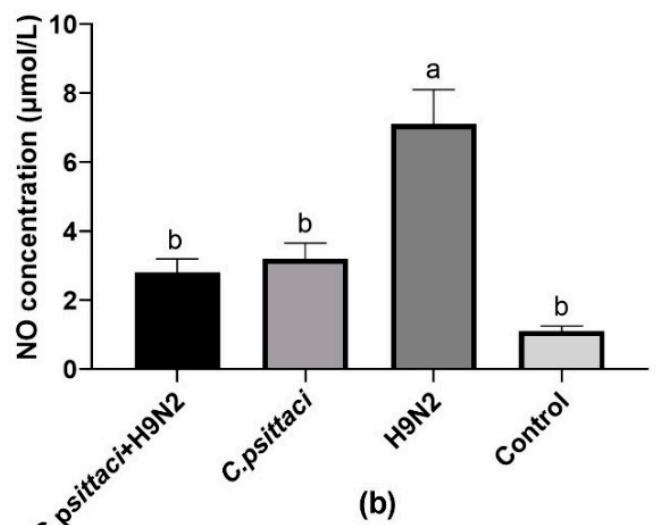

(b)

Figure 4. The effect of coinfection on nitric oxide (NO) synthesis. The NO synthesis of HD11 cells was tested post-infection with C. psittaci or H9N2 alone, or via coinfection. The NO synthesis of HD11 cells was tested at 12 hpi (a) and 24 hpi (b) after C. psittaci or H9N2 infection. A significant reduction of NO production was detected in the C. psittaci + H9N2 group, as compared to that of the H9N2 group at 24 hpi $(p<0.05)$. No significant difference was found between the $C$. psittaci + H9N2 group and the C. psittaci group at $24 \mathrm{hpi}(p>0.05)$.
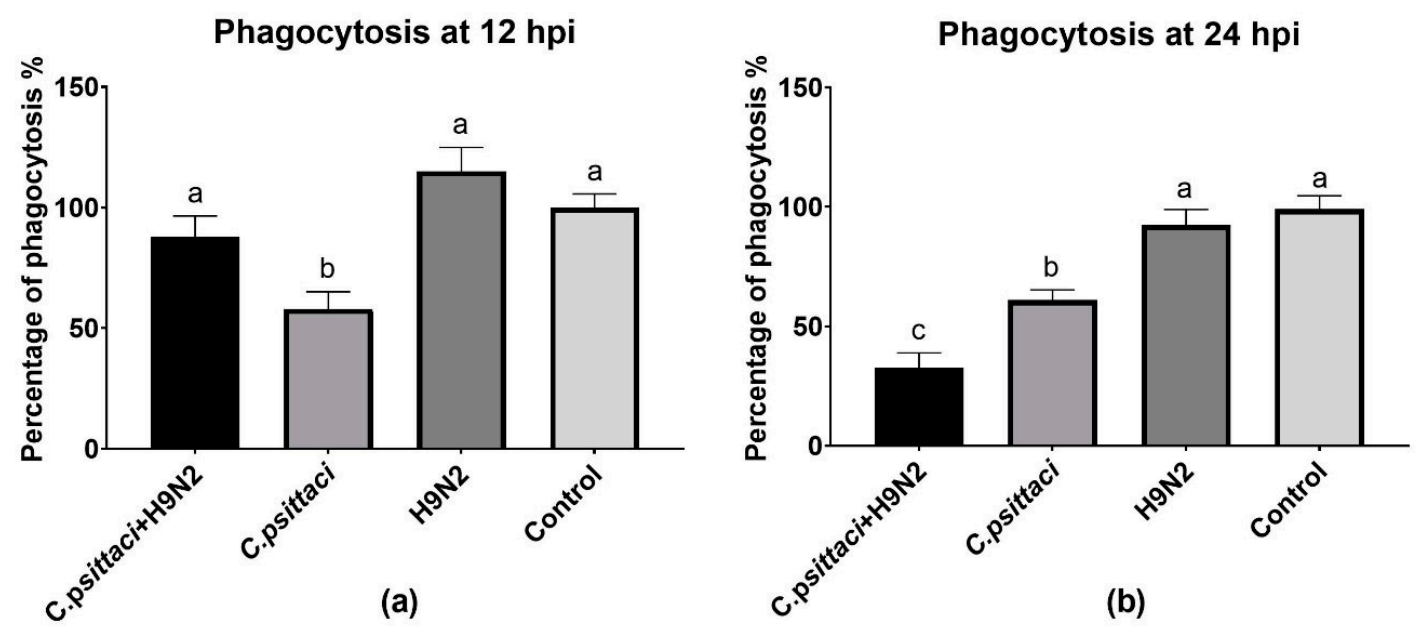

Figure 5. The effect of coinfection on cell phagocytosis. The cell phagocytosis of HD11 cells was tested post-infection with C. psittaci or H9N2 infection alone, or via coinfection. The cell phagocytosis of HD11 cells was tested at $12 \mathrm{hpi} \mathrm{(a)} \mathrm{and} \mathrm{at} 24 \mathrm{hpi}(\mathbf{b})$. The C. psittaci + H9N2 group induced a significant reduction of phagocytosis, as compared to the C. psittaci group $(p<0.05)$ or the H9N2 group $(p<0.01)$ at 24 hpi. No significant difference of phagocytic activity was found between the H9N2 group and the control group $(p>0.05)$.

\subsection{Coinfection with C. psittaci and H9N2 Polarized the Th2 Cytokines of HD11 Cells}

The expression of cytokines interleukin (IL)-1 $\beta$, IL-2, IL-6, IL-10, interferon gamma (IFN- $\gamma$ ) and tumor necrosis factor- $\alpha$ (TNF- $\alpha$ ) of HD11 cells was detected by test kits. As for Th1 cytokine secretions, higher expression of IL-1 $\beta$, IL-2, and IL-6 was induced in the C. psittaci + H9N2 group than in the C. psittaci group or the H9N2 group at 12 hpi $(p<0.01)$ (Figure $6 \mathrm{a}, \mathrm{b}, \mathrm{d})$. Later, greater TNF- $\alpha$ secretions were induced in the $C$. psittaci $+\mathrm{H} 9 \mathrm{~N} 2$ group and the H9N2 group than in the C. psittaci group at 24 hpi $(p<0.01)$ (Figure $6 \mathrm{~g}$ ). On the contrary, the secretions of IL-4 and IL-10 were increased significantly in the C. psittaci + H9N2 group, as compared to the H9N2 group or the $C$. psittaci group $(p<0.05)$ at 24 hpi (Figure 6c,e). 
IL-1 $\beta$

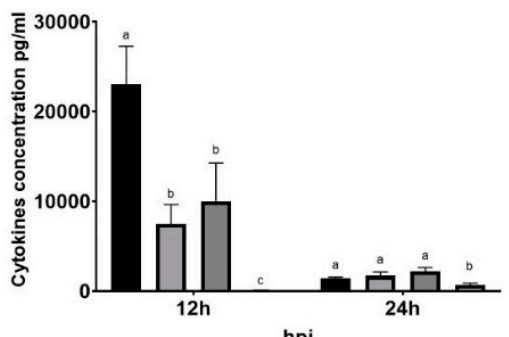

(a)

IL-4

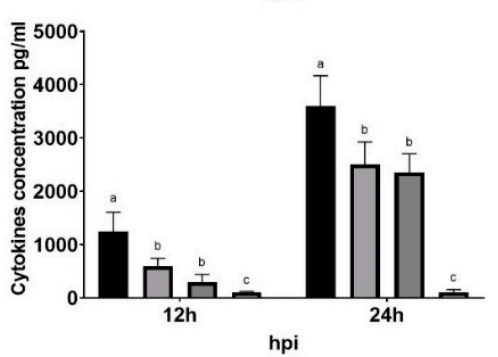

(c)

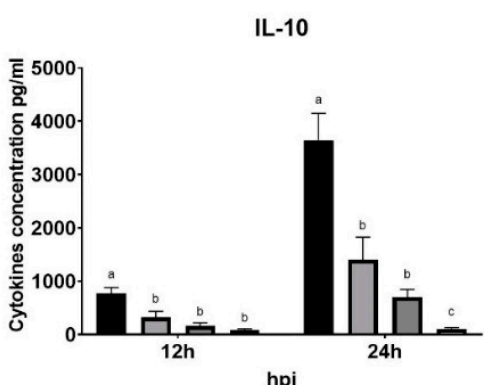

(e)

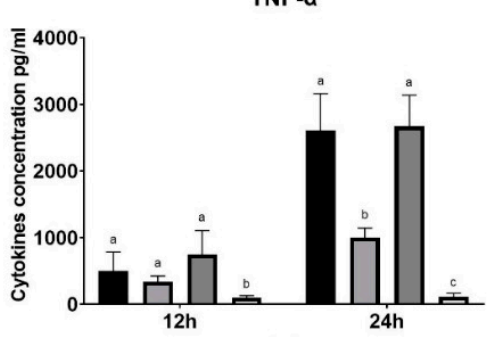

hpi
(g)
IL-2

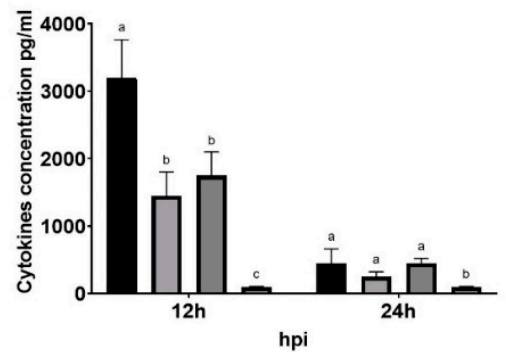

(b)

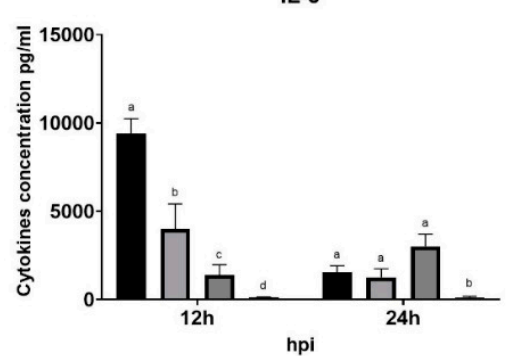

(d)

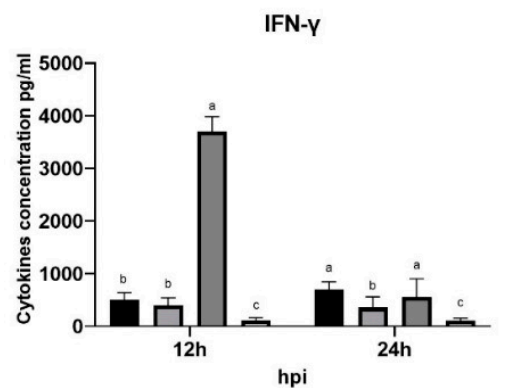

(f)

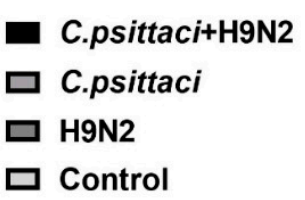

Figure 6. The effect of coinfection on cell cytokines. The levels of pro-/anti-inflammatory cytokines of HD11 cells were tested post-infection with C. psittaci or H9N2 infection alone, or via coinfection. The levels of (a) IL-1 $\beta$, (b) IL-2, (c) IL-4, (d) IL-6, (e) IL-10, (f) IFN- $\gamma$, and (g) TNF- $\alpha$ of HD11 cells were tested after $C$. psittaci and H9N2 infection. Higher expressions of IL-1 $\beta$, IL-2, and IL-6 were induced in the $C$. psittaci+H9N2 group than those of the $C$. psittaci group or the H9N2 group at 12 hpi $(p<0.05$ or $p<0.01)$. A significant increase in TNF- $\alpha$ secretions was induced in the C. psittaci + H9N2 group and in the H9N2 group compared to that of the C. psittaci group at 24 hpi. Moreover, Th2 cytokine expressions of the IL-4 and IL-10 were increased significantly in the C. psittaci + H9N2 group, as compared to the H9N2 group or the C. psittaci group $(p<0.01$ or $p<0.05)$ at 24 hpi.

\section{Discussion}

In the present study, we investigated the effect of chicken macrophage functions in response to coinfection with C. psittaci and H9N2 avian influenza virus. Our major finding was that coinfection 
with C. psittaci and H9N2 could significantly aggravate the mortality of HD11 cells compared to the effects of infection with C. psittaci or H9N2 alone. Moreover, the iNOS expression and enzyme activity, as well as NO concentration, of HD11 cells were significantly reduced compared to those of $C$. psittaci or H9N2 alone. In other words, coinfection of $C$. psittaci with H9N2 could stimulate HD11 cells to express less iNOS and NO compared to infection with H9N2 alone. In addition, coinfection of C. psittaci and H9N2 induced lower phagocytosis of HD11 cells than H9N2 or C. psittaci alone at 24 hpi. Furthermore, both the mRNA expression and cytokine levels of IL-4 and IL-10 were significantly increased at $24 \mathrm{hpi}$ in the C. psittaci + H9N2 group. On the contrary, the Th1 cytokines of IL-1 $\beta$, IL-2, and IL-6 were significantly increased in the $C$. psittaci $+\mathrm{H} 9 \mathrm{~N} 2$ group compared to those of $C$. psittaci or H9N2 alone at the early stage. Later, only TNF- $\alpha$ secretions were increased significantly compared to those of the C. psittaci group at $24 \mathrm{hpi}$. All the above data support our hypothesis that C. psittaci infection could aggravate the infection of $\mathrm{H} 9 \mathrm{~N} 2$ by impairing macrophage functions, leading to the outbreak of severe respiratory diseases.

In our previous study, we established an SPF chicken animal model with coinfection of $C$. psittaci and H9N2, and we found that C. psittaci infection increased the mortality of H9N2 by inhibiting humoral immunity and cellular immunity, as well as by altering the Th1/Th2 balance, ultimately weakening the immune system of the body [15]. It was the first report that C. psittaci infection can induce immune suppression in vivo and can lead to increased susceptibility to H9N2 infection. It also suggested that we should consider primary infection by C. psittaci in any respiratory disease, and should eradicate it during the treatment of avian respiratory disease. In addition, other studies have also reported the role of C. psittaci and H9N2 in the pathogenesis of coinfection. In this sense, coinfection is a common infection of two or more pathogens in the same host. Similar coinfection occurs frequently in human cases. For example, in 1918, in the human influenza virus pandemic, almost all cases of death were caused by bacteria mixed infection, and the additional bacterial infection greatly increased the risk of death [25]. Moreover, the combination of malaria and helminth is prevalent in less-developed countries [26]. Hence, identifying the primary pathogen of the mixed infection has been underestimated due to limited investigation. Traditionally, low pathogenic avian influenza virus triggers primary infection, and then the secondary infection of bacteria follows [27]. Since 2007, the outbreak of avian airsacculitis has been documented by the mixed infection of various pathogens [28].

In our study, coinfection with C. psittaci and H9N2 increased the mortality of HD11 cells in comparison with C. psittaci or H9N2 alone. Simultaneous infection with C. psittaci and H9N2 was able to increase the mortality of HD11 cells by decreasing iNOS activity and phagocytosis, indicating that coinfection might impair macrophage functions and facilitate the immune evasions of the two pathogens. Our discoveries are consistent with a previous report that showed macrophage functions were damaged post-infection with virulent C. psittaci [19].

Macrophages play an important role in innate immunity, such as phagocytosis, antiviral infection, and enhanced immune regulation. Pathogens infect the body and the monocytes after infection of the main target cells. After entering macrophages, Chlamydia can escape immune surveillance and transport to the whole body with macrophages, and thus macrophages act as the delivery system for Chlamydia [19]. Therefore, it is necessary to study how macrophages play a role in the host's immune response to the pathogen, as well as the pathogenesis of the pathogen, after the study of Chlamydia and H9N2 infection. The inducible nitric oxide synthase (iNOS) gene and its activity have been shown to be involved in the reaction of L-arginine decomposition into NO and L-citrulline. Endotoxin or cytokines, such as LPS and IFN- $\gamma$, can induce chicken macrophages to produce iNOS, and to further produce NO [29]. Our research shows that coinfection with C. psittaci and H9N2 could significantly decrease the iNOS expression level and enzyme activity, as well as the NO concentration, of HD11 cells compared to H9N2 or C. psittaci infection alone. However, the potential mechanism is unknown. The monocyte macrophage system has the function of phagocytosis and the killing of pathogens and tumor cells directly. In our study, we found that coinfection induced lower phagocytosis of 
HD11 cells compared to H9N2 infection. All this evidence illustrates the mechanism of macrophage dysfunction post-coinfection or after C. psittaci infection alone. Cytokines secreted by macrophages are also important components of their immune regulation. Here, several pro- and anti-inflammatory cytokines were determined by mRNA expression and ELISA cytokine kits. The role of Th1/Th2 cell cytokines is important in the immune response to chlamydial infection. It appears that the Th1 CD4 cell response plays a dominant role in protective immunity, while Th2 CD4 cytokines (particularly IL-10) play a role in the immunopathology of chlamydial infection. Products of Th2 cells do not facilitate the production of IFN- $\gamma$ or inhibit Chlamydia growth [30]. TNF- $\alpha$ regulates critical cell functions, including cell proliferation, survival, differentiation, and apoptosis. Macrophages are the major producers of TNF- $\alpha$, and TNF- $\alpha$ has been shown to play a pivotal role in orchestrating the cytokine cascade in many inflammatory diseases [31]. Increased TNF- $\alpha$ levels have been associated with atherosclerosis and coronary heart disease post-infection with Chlamydia pneumoniae (C. pneumoniae) [32]. IL-10 is an anti-inflammatory cytokine known to play a critical role in chronic infections caused by intra-cellular organisms. During chlamydial infection, high IL-10 secretion was shown to be associated with pathogenesis in a mouse model of Chlamydia trachomatis (C. trachomatis) infection [33]. In the present study, high TNF- $\alpha$ production was induced by coinfection with C. psittaci and H9N2, and this might be associated with increasing the increased mortality of the HD11 cells. In our results, the expression of IL-4 and IL-10 were increased significantly in the coinfection groups, suggesting that chlamydial infection mediated the polarization of Th1/Th2 to the Th2 direction. The dominant role of Th2 cytokines hampers immune function, so that pathogens can evade immune surveillance and immune attacks. The Th2 polarization was consistent with our previous data, implying that immune suppression is aggravated post-artificial infection with H9N2 and C. psittaci [15].

In conclusion, coinfection often increases disease severity in both humans and animals. Understanding the mechanisms and effects of coinfection will improve the understanding of the mechanism of mixed infection. In this study, the macrophage functions were exacerbated by reducing phagocytosis post-coinfection. Also, the polarization of IL-4 and IL-10 expressions might contribute to macrophage dysfunction and facilitate $\mathrm{H} 9 \mathrm{~N} 2$ circulations by reducing virus clearance in host cells. In addition, further findings of this study show that not only does C. psittaci aggravate H9N2 infection, but $\mathrm{H} 9 \mathrm{~N} 2$ can also increase the mortality caused by C. psittaci infection. Whether this is beneficial to the infection and spread of C. psittaci remains to be confirmed. These findings suggest that we should consider the primary and latent infection of C. psittaci in respiratory disease and should eradicate C. psittaci during treatment.

\section{Conclusions}

In conclusion, coinfection often increases disease severity in both humans and animals. Understanding the mechanisms and effects of coinfection will improve the understanding of the common pathogenicity mechanisms. Since 2007, severe respiratory infections and avian airsacculitis in chickens in many parts of China have been the result of coinfection with bacteria and viruses. The role of viral-bacterial coinfection in animal-to-human transmission of infectious agents has not received enough attention, and should be emphasized in future investigations. We have established a SPF chicken model of coinfection with C. psittaci and H9N2 in vivo. At this point, it is urgent to continue to study cell models of coinfection of C. psittaci and H9N2 in vitro. In this study, we did such work and found that infection with $C$. psittaci will increase the replication of H9N2, decrease the iNOS-NO pathway, and raise the IL- 6 and IL-10 expression of HD11 cells by H9N2 infection. At the same time, C. psittaci infection can also reduce the phagocytosis of macrophages. Like the results of previous animal models, we found that C. psittaci can reduce the function of immune cells in many ways, thus aggravating the susceptibility of H9N2. In addition, the further findings of this study are that not only does C. psittaci aggravate H9N2 infection, but also H9N2 can increase the mortality caused by C. psittaci infection. Whether this is beneficial to the infection and spread of C. psittaci remain to 
be confirmed. These findings suggest that we should consider the primary and latent infection of C. psittaci in respiratory diseases, and should eradicate C. psittaci during treatment.

Author Contributions: C.H. conceived and designed the research. J.C., Y.G., G.X., and Q.Z. performed the experiments. Z.Z., Q.L., and Y.W. analyzed the data. J.C. wrote the paper. All authors read and approved the manuscript.

Funding: This work was supported by the National Natural Science Foundation of China (grant nos. 31672517 and 31272542) and Cheng He. The investigation was also partially supported by the Ministry of Science and Technology (MoST) of China (grant nos. 2016YFD0500906 and 2016YFE0127100).

Acknowledgments: The authors are grateful to Francis O. Eko for many helpful suggestions during the experiments, and Ahrar Khan at University of Agriculture, Faisalabad, Pakistan is gratefully acknowledged for language revision.

Conflicts of Interest: The authors declare no competing financial interests.

\section{References}

1. Knittler, M.R.; Sachse, K. Chlamydia psittaci: Update on an underestimated zoonotic agent. Pathog. Dis. 2015, 73, 1-15. [CrossRef] [PubMed]

2. Meyer, K.F.; Eddie, B. Human carrier of the psittacosis virus. J. Infect. Dis. 1951, 88, 109-125. [CrossRef] [PubMed]

3. Harkinezhad, T.; Geens, T.; Vanrompay, D. Chlamydophila psittaci infections in birds: A review with emphasis on zoonotic consequences. Vet. Microbiol. 2009, 135, 68-77. [CrossRef] [PubMed]

4. Dickx, V.; Kalmar, I.D.; Tavernier, P.; Vanrompay, D. Prevalence and genotype distribution of Chlamydia psittaci in feral Canada geese (Branta canadensis) in Belgium. Vector Borne Zoonotic Dis. 2013, 13, 382-384. [CrossRef] [PubMed]

5. Cong, W.; Huang, S.Y.; Zhang, X.X.; Zhou, D.H.; Xu, M.J.; Zhao, Q.; Qian, A.D.; Zhu, X.Q. Chlamydia psittaci exposure in pet birds. J. Med. Microbiol. 2014, 63, 578-581. [CrossRef] [PubMed]

6. Cong, W.; Huang, S.Y.; Zhang, X.Y.; Zhou, D.H.; Xu, M.J.; Zhao, Q.; Song, H.Q.; Zhu, X.Q.; Qian, A.D. Seroprevalence of Chlamydia psittaci infection in market-sold adult chickens, ducks and pigeons in north-western China. J. Med. Microbiol. 2013, 62, 1211-1214. [CrossRef]

7. Ling, Y.; Chen, H.; Chen, X.; Yang, X.; Yang, J.; Bavoil, P.M.; He, C. Epidemiology of Chlamydia psittaci Infection in Racing Pigeons and Pigeon Fanciers in Beijing, China. Zoonoses Public Health 2015, 62, 401-406. [CrossRef]

8. Wang, X.; Zhang, N.Z.; Ma, C.F.; Zhang, X.X.; Zhao, Q.; Ni, H.B. Epidemiological Investigation and Genotype of Chlamydia Exposure in Pigeons in Three Provinces in Northern China. Vector Borne Zoonotic Dis. 2018, 18, 181-184. [CrossRef]

9. Karpinska, T.A.; Kozaczynski, W.; Niemczuk, K.; Jasik, A.; Kycko, A.; Reichert, M. Mixed infection by fowlpox virus and Chlamydophila psittaci in a commercial laying hen flock. Acta Vet. Hung. 2014, 62, 42-51. [CrossRef]

10. Umar, S.; Sarfraz, S.; Attique, A.M.M. Emerging threat of H9N2 viruses in poultry of Pakistan and vaccination strategy. Worlds Poult. Sci. J. 2016, 72, 343-352. [CrossRef]

11. Sun, Y.; Liu, J. H9N2 influenza virus in China: A cause of concern. Protein Cell 2015, 6, 18-25. [CrossRef]

12. Ma, M.J.; Zhao, T.; Chen, S.H.; Xia, X.; Yang, X.X.; Wang, G.L.; Fang, L.Q.; Ma, G.Y.; Wu, M.N.; Qian, Y.H.; et al. Avian Influenza A Virus Infection among Workers at Live Poultry Markets, China, 2013-2016. Emerg Infect. Dis. 2018, 24, 1246-1256. [CrossRef] [PubMed]

13. Jaleel, S.; Younus, M.; Idrees, A.; Arshad, M.; Khan, A.U.; Ehtisham-Ul-Haque, S.; Zaheer, M.I.; Tanweer, M.; Towakal, F.; Munibullah; et al. Pathological Alterations in Respiratory System During Co-infection with Low Pathogenic Avian Influenza Virus (H9N2) and Escherichia Coli in Broiler Chickens. J. Vet. Res. 2017, 61, 253-258. [CrossRef] [PubMed]

14. Aouini, R.; Laamiri, N.; Ghram, A. Viral interference between low pathogenic avian influenza H9N2 and avian infectious bronchitis viruses in vitro and in ovo. J. Virol. Methods 2018, 259, 92-99. [CrossRef] [PubMed]

15. Chu, J.; Zhang, Q.; Zhang, T.; Han, E.; Zhao, P.; Khan, A.; He, C.; Wu, Y. Chlamydia psittaci infection increases mortality of avian influenza virus H9N2 by suppressing host immune response. Sci. Rep. 2016, 6, 29421. [CrossRef] [PubMed] 
16. Chu, J.; Zhang, Q.; Zuo, Z.; El-Ashram, S.; Guo, Y.; Zhao, P.; Huang, S.; He, C.; Khan, A. Co-infection of Chlamydia psittaci with H9N2, ORT and Aspergillus fumigatus contributes to severe pneumonia and high mortality in SPF chickens. Sci. Rep. 2017, 7, 13997. [CrossRef]

17. Miyairi, I.; Laxton, J.D.; Wang, X.; Obert, C.A.; Arva Tatireddigari, V.R.; van Rooijen, N.; Hatch, T.P.; Byrne, G.I. Chlamydia psittaci genetic variants differ in virulence by modulation of host immunity. J. Infect. Dis. 2011, 204, 654-663. [CrossRef]

18. Qiu, H.; Fan, Y.; Joyee, A.G.; Wang, S.; Han, X.; Bai, H.; Jiao, L.; Van Rooijen, N.; Yang, X. Type I IFNs enhance susceptibility to Chlamydia muridarum lung infection by enhancing apoptosis of local macrophages. J. Immunol. 2008, 181, 2092-2102. [CrossRef]

19. Beeckman, D.S.; Vanrompay, D.C. Biology and intracellular pathogenesis of high or low virulent Chlamydophila psittaci strains in chicken macrophages. Vet. Microbiol. 2010, 141, 342-353. [CrossRef]

20. Martinez, F.O.; Gordon, S. The M1 and M2 paradigm of macrophage activation: Time for reassessment. F1000Prime Rep. 2014, 6, 13. [CrossRef]

21. Pan, Q.; Liu, A.; Zhang, F.; Ling, Y.; Ou, C.; Hou, N.; He, C. Co-infection of broilers with Ornithobacterium rhinotracheale and H9N2 avian influenza virus. BMC Vet. Res. 2012, 8, 104. [CrossRef]

22. Tay, F.P.; Huang, M.; Wang, L.; Yamada, Y.; Liu, D.X. Characterization of cellular furin content as a potential factor determining the susceptibility of cultured human and animal cells to coronavirus infectious bronchitis virus infection. Virology 2012, 433, 421-430. [CrossRef] [PubMed]

23. Nang, N.T.; Lee, J.S.; Song, B.M.; Kang, Y.M.; Kim, H.S.; Seo, S.H. Induction of inflammatory cytokines and Toll-like receptors in chickens infected with avian H9N2 influenza virus. Vet. Res. 2011, 42, 64. [CrossRef] [PubMed]

24. Livak, K.J.; Schmittgen, T.D. Analysis of relative gene expression data using real-time quantitative PCR and the 2(-Delta Delta C(T)) Method. Methods 2001, 25, 402-408. [CrossRef] [PubMed]

25. Chertow, D.S.; Memoli, M.J. Bacterial coinfection in influenza: A grand rounds review. JAMA 2013, 309, 275-282. [CrossRef] [PubMed]

26. Getie, S.; Wondimeneh, Y.; Getnet, G.; Workineh, M.; Worku, L.; Kassu, A.; Moges, B. Prevalence and clinical correlates of Schistosoma mansoni co-infection among malaria infected patients, Northwest Ethiopia. BMC Res. Notes 2015, 8, 480. [CrossRef]

27. Bano, S.; Naeem, K.; Malik, S.A. Evaluation of pathogenic potential of avian influenza virus serotype H9N2 in chickens. Avian Dis. 2003, 47, 817-822. [CrossRef]

28. Pan, Q.; Liu, A.; He, C. Co-infection of Ornithobacterium rhinotracheale with Streptococcus zooepidemicus in chickens. Avian Dis. 2012, 56, 680-684. [CrossRef]

29. Hussain, I.; Qureshi, M.A. Nitric oxide synthase activity and mRNA expression in chicken macrophages. Poult. Sci. 1997, 76, 1524-1530. [CrossRef]

30. Diehl, S.; Anguita, J.; Hoffmeyer, A.; Zapton, T.; Ihle, J.N.; Fikrig, E.; Rincon, M. Inhibition of Th1 differentiation by IL-6 is mediated by SOCS1. Immunity 2000, 13, 805-815. [CrossRef]

31. Parameswaran, N.; Patial, S. Tumor necrosis factor-alpha signaling in macrophages. Crit. Rev. Eukaryot. Gene Expr. 2010, 20, 87-103. [CrossRef] [PubMed]

32. Campbell, L.A.; Nosaka, T.; Rosenfeld, M.E.; Yaraei, K.; Kuo, C.C. Tumor necrosis factor alpha plays a role in the acceleration of atherosclerosis by Chlamydia pneumoniae in mice. Infect. Immun. 2005, 73, 3164-3165. [CrossRef] [PubMed]

33. Yang, X.; Gartner, J.; Zhu, L.; Wang, S.; Brunham, R.C. IL-10 gene knockout mice show enhanced Th1-like protective immunity and absent granuloma formation following Chlamydia trachomatis lung infection. J. Immunol. 1999, 162, 1010-1017. [PubMed]

(C) 2020 by the authors. Licensee MDPI, Basel, Switzerland. This article is an open access article distributed under the terms and conditions of the Creative Commons Attribution (CC BY) license (http://creativecommons.org/licenses/by/4.0/). 